\title{
EM DEFESA DE UM BIDIMENSIONALISMO SEMÂNTICO
}

\author{
In defense of a two-dimensional semantic
}

\author{
Carolina Muzitano *
}

Resumo: partir dos trabalhos de Kripke sobre mundos possíveis e designadores rígidos, muitos filósofos passaram a defender que os conteúdos dos nossos estados mentais são amplos, pois a sua individuação dependeria das nossas relações causais com o nosso ambiente físico e/ou social. Contudo, tal conteúdo amplo reabre a questão dos "casos fregeanos", pois sentenças epistemicamente distintas possuirão o mesmo conteúdo amplo. Uma recente resposta a esta dificuldade é a de afirmar que estados mentais possuem uma dupla dimensão em relação aos seus conteúdos, compatibilizando uma individuação fina dos conteúdos com certas conclusões externalistas. $\mathrm{O}$ objetivo deste trabalho é o de apresentar os argumentos de Frank Jackson em defesa de um bidimensionalismo semântico.

Palavras-chave: bidimensionalismo, conteúdo amplo, conteúdo estreito, Frank Jackson.

\begin{abstract}
Since Kripke's works about possible worlds and rigid designators, many philosophers start to defend that the contents of our mental states are wide, because its individuation depends on our causal relations with our physic and/or social environment. However, such wide content reopen the question about the "fregean cases", because epistemically distinct sentences will have the same wide content. One recent approach to this difficulty is to say that mental states have a double dimension in relation to the contents, compatibilizing a fine-grained individuation of the contents with certain externalist conclusions. The aim of this paper is to present the Frank Jackson's arguments in defense of a two-dimensional semantic.

Keywords: two-dimensional, wide content, narrow content, Frank Jackson.
\end{abstract}

* Doutoranda em Filosofia pela Universidade do Estado do Rio de Janeiro (UERJ). Bolsista Capes carolinamuzitano@gmail.com

\begin{tabular}{|c|c|c|c|c|c|}
\hline intuitio & $\begin{array}{c}\text { ISSN } \\
1983-4012\end{array}$ & Porto Alegre & Vol.8 $-\mathrm{N}^{\mathrm{o}} .1$ & $\begin{array}{c}\text { Junho } \\
2015\end{array}$ & p.46-63 \\
\hline
\end{tabular}




\section{Introdução}

Crenças e outros estados mentais são comumente caracterizados como sendo estados representacionais: crenças representam como consideramos que as coisas são; desejos representam como nós gostaríamos que elas fossem, e assim por diante ${ }^{1}$. E representar é fazer uma divisão no espaço lógico, ou seja, dividi-lo entre aquilo que é consistente com o que está sendo representado de um lado e aquilo que é inconsistente, de outro. Nesta perspectiva, podemos afirmar que o conjunto de mundos W que são consistentes com o pensamento $P$ é o conteúdo deste estado mental intencional $P$. Por exemplo, o conteúdo da minha crença "está chovendo bastante agora" consiste no conjunto de mundos possíveis que verifica tal pensamento, ou seja, o conjunto de mundos onde há chuva em um certo espaço e1 (a localidade onde acredito que esteja chovendo) e em um certo tempo t1, que é o tempo do proferimento.

Em meados da década de 70, alguns filósofos começaram a defender que os conteúdos dos estados e eventos mentais são amplos, ou seja, que tais conteúdos seriam determinados pelas relações (em sua grande maioria, de natureza causal) que o sujeito entretém com o ambiente externo, seja ele físico ou social. Comumente, tal defesa está associada a uma teoria externalista sobre o significado dos termos. Segundo tal linha filosófica, vários dos estados e eventos mentais representacionais, são constitutivamente o que são em virtude das relações que vigem entre o indivíduo que detém tais estados e uma realidade mais ampla, seja ela o mundo físico externo ou o ambiente social no qual o sujeito está inserido.

Os principais autores que criaram e impulsionaram tal defesa da noção de conteúdo amplo foram Saul Kripke, Hilary Putnam e Tyler Burge. Kripke não é propriamente um autor externalista, mas a sua teoria da referência direta parece implicar a consequência de que os conteúdos dos estados mentais que contém nomes próprios ${ }^{2}$ serão, necessariamente, amplos. Além disso, Kripke fornece, com a sua nova elaboração da lógica modal ${ }^{3}$, o material necessário para os experimentos mentais em defesa do conteúdo amplo. Segundo ele, não devemos pensar mundos possíveis como mundos isolados, pois todo mundo

\footnotetext{
${ }^{1}$ Embora não seja controverso afirmar na filosofia contemporânea que crenças são estados representacionais, o mesmo não pode ser dito em relação a estados como desejos ou sensações, por exemplo. Contudo, sigo aqui a caracterização dada por Jackson (2003a). Tal afirmação em relação aos conteúdos de certos estados (como desejos) como sendo representacionais não gerará um problema em relação à aceitação da tese bidimensionalista defendida no artigo, visto que os argumentos utilizarão apenas estados mentais de crença.

${ }^{2}$ Segundo Kripke, podemos expressar certas sentenças como "Aristóteles poderia não ter sido professor de Alexandre, o Grande" devido ao fato de que nomes próprios têm as suas referências fixadas de forma direta, sem recorrer a nenhuma descrição definida. Dessa forma, o nome "Aristóteles" tem como referência o próprio Aristóteles. Embora Kripke não trate sua defesa da referência direta em termos de estados mentais, podemos afirmar que todo estado mental que utilize nomes próprios (como a crença "Aristóteles poderia não ter sido aluno de Platão") terá um conteúdo amplo, pois as referências dos nomes próprios serão determinadas por propriedades extrínsecas ao indivíduo do estado mental em questão e, portanto, a individuação do conteúdo deste estado mental dependerá de certas relações causais com a res relevante.

${ }^{3}$ Cf. KRIPKE, S. (1972). Naming and Necessity. In: The Philosophy of Language, ed. A. P. Martinich, 3.ed. Oxford: University Press, 1996.
}

\begin{tabular}{|c|c|l|l|l|l|}
\hline intuitio & $\begin{array}{c}\text { ISSN } \\
1983-4012\end{array}$ & Porto Alegre & Vol.8 $-\mathrm{N}^{\mathrm{o}} .1$ & $\begin{array}{c}\text { Junho } \\
2015\end{array}$ & p.46-63 \\
\hline
\end{tabular}


possível tem relação com o nosso mundo, ou seja, com o mundo atual. E isso porque ao descrevermos mundos contrafactuais, o fazemos usando a nossa língua com os nossos significados e as nossas referências ${ }^{4}$.

A partir destes experimentos mentais, Putnam e Burge tentam mostrar que, ao alterarmos o ambiente externo no qual o indivíduo se encontra nas situações possíveis, enquanto mantemos intactas as propriedades internas do indivíduo, os conteúdos dos estados mentais também se alterarão ${ }^{5}$. Putnam ${ }^{6}$ argumentará através do seu famoso experimento mental da Terra Gêmea, que a determinação do significado dos termos de espécie natural (como "água" ou "olmo") depende da própria natureza essencial da res relevante, sendo tais termos, assim como os nomes próprios na teoria de Kripke, designadores rígidos $^{7}$. O que a teoria de Putnam mostra, grosseiramente, é que mesmo que dois indivíduos (o indivíduo no mundo real e a sua contraparte fisicamente idêntica em um mundo possível) estejam no mesmo estado mental (ou seja, tenham o mesmo pensamento, como "água é molhada"), os conteúdos dos seus pensamentos divergirão se a propriedade dita essencial da res em questão for diferente. Por exemplo, suponha que, na Terra Gêmea, o líquido transparente que seus habitantes bebem e nomeiam como "água" tem todas as propriedades superficiais que água tem como ser incolor, insípida e inodora, mas, diferentemente do caso da água, tal líquido na Terra Gêmea não é $\mathrm{H}_{2} \mathrm{O}$, mas sim XYZ. Dessa forma, os pensamentos da contraparte na Terra Gêmea sobre esta "coisa aquosa" terão um conteúdo distinto dos pensamentos do falante da Terra sobre água. Burge ${ }^{8}$, posteriormente, mostrará que podemos aplicar o mesmo tipo de experimento mental a praticamente todo tipo de termo, pois a determinação do significado dos termos e a individuação dos conteúdos dos estados mentais dependem também do ambiente social no qual o sujeito está inserido. Ambientes físicos e/ou sociais distintos implicarão conteúdos dos estados

\footnotetext{
4 "When I say that a designator is rigid, and designates the same thing in all possible worlds, I mean that, as used in our language, it stands for that thing, when we talk about counterfactual situations. I don't mean, of course, that there mightn't be counterfactual situations in which in the other possible worlds people actually spoke a different language. [...] in describing that world [um mundo possível], we use English with our meanings and our references". KRIPKE, S. (1972). Naming and Necessity. In: The Philosophy of Language, ed. A. P. Martinich, 3.ed. Oxford: University Press, 1996, p. 261.

${ }^{5}$ A teoria de Putnam diz respeito apenas sobre o significado dos termos de tipo natural, sem envolver afirmações sobre conteúdos de estados mentais. Da mesma forma que podemos aplicar a teoria de Kripke sobre nomes próprios à estados mentais, como na nota 1 , podemos aplicar a tese semântica de Putnam aos estados mentais que utilizam termos de tipo natural. Além disso, como Burge afirma em "Other Bodies", as diferenças no ambiente externo entre as duas situações possíveis no experimento mental de Putnam afetarão as ocorrências oblíquas (os conteúdos dos estados mentais) do indivíduo e da sua contraparte, sendo tal conteúdo, portanto, amplo. Cf. BURGE, T. (1982). Other Bodies. In: Foundations of Mind, Clarendon Press, Oxford, 2007, p. 86.

${ }^{6}$ Cf. PUTNAM, H. (1975). The Meaning of "Meaning". In: Mind, Language and Reality. Philosophical Papers, v. 2. Cambridge: Cambridge University Press, 1995.

${ }^{7}$ Dizemos que um termo é um designador rígido quando tem a mesma referência em todo mundo possível. Assim, "água" é um designador rígido, pois refere-se $\mathrm{a}_{2} \mathrm{O}$ em todos os mundos.

${ }^{8}$ Cf. BURGE, T. (1979). Individualism and the Mental. In: Foundations of Mind. Oxford: Clarendon Press, 2007, p. $100-150$.
}

\begin{tabular}{|c|c|c|c|c|c|}
\hline intuitio & $\begin{array}{c}\text { ISSN } \\
1983-4012\end{array}$ & Porto Alegre & Vol.8 $-\mathrm{N}^{\mathrm{o} .1}$ & $\begin{array}{c}\text { Junho } \\
2015\end{array}$ & p.46-63 \\
\hline
\end{tabular}


mentais dos sujeitos também distintos, mesmo que tais indivíduos sejam física e historicamente idênticos. Assim, segundo tais autores, os conteúdos dos estados mentais representacionais são amplos.

Contudo, tal conteúdo amplo não parece capturar de modo completo o conteúdo representacional de uma crença. Por exemplo, de acordo com tal teoria externalista, quando penso "a garrafa com água está gelada", este estado mental tem o mesmo conteúdo da sentença "a garrafa com $\mathrm{H}_{2} \mathrm{O}$ está gelada", pois ambas dividem o espaço lógico da mesma forma. Todo mundo possível que verifica sentenças sobre $\mathrm{H}_{2} \mathrm{O}$ verificará também as sentenças sobre água, pois água é necessariamente $\mathrm{H}_{2} \mathrm{O}$. Entretanto, não parece plausível afirmar que a minha crença sobre água é, necessariamente, uma crença sobre $\mathrm{H}_{2} \mathrm{O}$, pois posso não saber que água é $\mathrm{H}_{2} \mathrm{O}$. Em tal perspectiva externalista, portanto, o paradoxo de Frege não parece ter solução, pois não há uma individuação fina dos conteúdos dos estados mentais que permita distinguir minhas crenças sobre água das minhas crenças sobre $\mathrm{H}_{2} \mathrm{O}^{10}$.

Ao mesmo tempo, os argumentos externalistas parecem fortes demais para serem abandonados. $\mathrm{O}$ uso que fazemos dos nossos termos, o modo como aprendemos uma língua e, como veremos mais detalhadamente a seguir, fatores como deferencialidade e compreensão incompleta indicam que os significados das palavras que usamos estão necessariamente relacionados (de maneira causal) com um ambiente externo, seja ele físico ou social. Além disso, há um sentido no qual parece plausível afirmar que os conteúdos dos estados mentais sobre água do nosso exemplo acima são os mesmos: se água é necessariamente $\mathrm{H}_{2} \mathrm{O}$, então quando penso sobre água estou pensando sobre $\mathrm{H}_{2} \mathrm{O}$, pois aquilo a que me refiro quando utilizo a palavra "água" é, no final das contas, $\mathrm{H}_{2} \mathrm{O}$.

Uma alternativa possível é adotar um posicionamento bidimensionalista em relação aos conteúdos dos nossos estados mentais, compatibilizando um tipo de individuação fina de tais conteúdos

\footnotetext{
${ }^{9}$ Grosseiramente, o "paradoxo de Frege" afirma que certas sentenças de identidade como "água é $\mathrm{H}_{2} \mathrm{O}$ ” não são tautológicas, pois há aquisição de conhecimento envolvido, portanto sua forma lógica não pode ser equivalente a "a = a". Mas se a determinação do conteúdo envolve apenas os objetos referenciados, ou seja, se tal conteúdo for considerado como amplo, o paradoxo não é resolvido: a sentença, mesmo tendo valor cognitivo, teria a forma lógica de uma tautologia (que, por definição, não nos acrescenta nenhum conhecimento). Se "água" refere-se a $\mathbf{x}$ em todo mundo possível, e " $\mathrm{H}_{2} \mathrm{O}$ " refere-se a $\mathbf{x}$ em todo mundo possível, o conteúdo amplo de "água é $\mathrm{H}_{2} \mathrm{O}$ " teria a forma " $\mathrm{x}$ = x". Dessa forma, o que tal paradoxo nos mostra, segundo Frege, é que deve haver algo a mais na determinação do conteúdo das sentenças, ou seja, tais sentenças devem ser individuadas de forma fina [fine-grained way].

${ }^{10}$ Burge afirma que tais substituições de um termo por outro co-extensional não podem ser feitas desse modo, pois estados mentais como crenças ocorrem obliquamente. Cf. BURGE, T. (2006). Postscript to 'Individualism and the Mental'. In: Foundations of Mind. Oxford: Clarendon Press, 2007, p. 160-161. Segundo ele, as conclusões do seu experimento mental da artrite não são sobre a determinação dos conteúdos representacionais dos estados mentais de um sujeito, mas sim sobre a natureza de tais estados mentais ["I emphasize that anti-individualism is about the nature of the mental, not about the nature of representational content.". BURGE, T. (2006). Postscript to 'Individualism and the Mental'. In: Foundations of Mind. Oxford: Clarendon Press, 2007, p. 156]. Contudo, como veremos mais a frente: todo o argumento de Burge está baseado em afirmações sobre a individuação de tais conteúdos representacionais e, portanto, tais implicações sobre a "amplidade" do conteúdo parecem inevitáveis. Além disso, Burge não apresenta, pelo menos nos trabalhos apresentados na bibliografia, nenhuma afirmação de como tais estados ocorreriam obliquamente estando os sujeitos relacionados causalmente com o ambiente físico e social - ou seja, como não permitir tal substituição sendo tais conteúdos amplos.
}

\begin{tabular}{|c|c|l|l|l|l|}
\hline intuitio & $\begin{array}{c}\text { ISSN } \\
1983-4012\end{array}$ & Porto Alegre & Vol.8 $-\mathrm{N}^{\mathrm{o}} .1$ & $\begin{array}{c}\text { Junho } \\
2015\end{array}$ & p.46-63 \\
\hline
\end{tabular}


representacionais com os resultados externalistas acerca da deferencialidade e compreensão incompleta dos termos que usamos. Segundo Frank Jackson, embora os argumentos nos moldes da Terra Gêmea nos mostrem que a determinação do conteúdo do estado mental depende das relações que o indivíduo entretém com o ambiente externo e, portanto, os conteúdos são amplos, aquilo que o sujeito pensa e sabe sobre o mundo ao seu redor também é relevante na individuação do conteúdo do seu estado mental ${ }^{11}$. Isso significa que certas propriedades intrínsecas ao indivíduo, como as descrições que ele associa aos termos que utiliza, também individuam os conteúdos dos seus estados mentais, portanto, tais conteúdos também são estreitos. Assim, segundo Jackson, há uma dupla dimensão envolvida nos nossos estados mentais: tais estados tanto possuem conteúdos amplos quanto conteúdos estreitos.

Em contraste com o uso dos mundos possíveis padrão presente nos experimentos mentais a semântica bidimensional atribui extensões e condições de valor de verdade aos estados mentais relativos a dois parâmetros de mundos possíveis, primeiro, considerando um mundo possível como sendo o atual e, segundo, considerando um mundo possível como um contrafactual. Dessa forma, o estado mental em questão terá duas intensões, uma que mapeia a referência em um mundo possível tomado como atual e outra que mapeia nos mundos possíveis contrafactuais. Tendo duas intensões um estado mental representacional possuirá, então, dois conteúdos. O objetivo deste trabalho é apresentar argumentos em favor de tal semântica bidimensionalista, restringindo o escopo da discussão à teoria apresentada por Jackson $^{12}$.

\section{Conteúdos Amplos}

Vejamos, primeiramente, os experimentos mentais de Putnam e Burge em favor do conteúdo amplo. O exemplo mais famoso de Putnam é o seu experimento da Terra Gêmea ${ }^{13}$. Por ser um exemplo bastante conhecido e utilizado apresentarei apenas uma versão resumida dele. Nesse experimento mental,

11 "The determination of content, both semantic and intentional, involves, in some broad sense, causal relations between subject and environment. But this is consistent with (representational) content being narrow in the sense of not being environmental, in the sense of not being a property we can change merely by transport from one environment to another." JACKSON, F. Narrow Content and representation - or Twin Earth revisited. In: Proceedings and Addresses of the American Philosophical Association. v. 77, n. 2, pp. 55-70, Nov., 2003a, p. 4. Disponível em: http://phil.arts.cuhk.edu.hk/ phidept/TCIVP/jackson/FJ\%20Narrow\%20content.pdf.

${ }^{12}$ Decidi restringir apenas à tese de Jackson por dois motivos. Primeiro, porque o bidimensionalismo epistêmico, em contraposição a um bidimensionalismo contextual como o de Stalnaker, parece capturar melhor uma noção de conteúdo estreito que afirme as nossas intuições sobre conteúdos representacionais. E, segundo, porque a teoria de Jackson, em contraposição à teoria bidimensional epistêmica de Chalmers, exige menos em relação à racionalidade humana, dessa forma, parece ser uma que pode ser mais facilmente aceita. A teoria de Jackson é mais moderada do que a de Chalmers.

${ }^{13}$ Cf. PUTNAM, H. (1975). The Meaning of "Meaning". In: Mind, Language and Reality - Philosophical Papers. v. 2. Cambridge: Cambridge University Press, 1995, p. 223-226.

\begin{tabular}{|c|c|l|l|l|l|}
\hline intuitio & $\begin{array}{c}\text { ISSN } \\
1983-4012\end{array}$ & Porto Alegre & Vol.8 $-\mathrm{N}^{\circ} .1$ & $\begin{array}{c}\text { Junho } \\
2015\end{array}$ & p.46-63 \\
\hline
\end{tabular}


supomos um planeta imaginário que é tanto fisicamente quanto histórica/culturalmente idêntico à Terra, exceto por um detalhe: na Terra Gêmea, o líquido que é incolor, insípido, potável e utilizado para matar a sede, que cai em forma de chuva e preenche rios, mares, etc. ${ }^{14}$ não é composto por hidrogênio e oxigênio, na verdade, é um líquido cuja fórmula química é extremamente complexa, sendo abreviada como XYZ. Supomos também que $\mathrm{Adam}_{1}$, um típico falante da Terra ${ }^{15}$, não sabe que água consiste de hidrogênio e oxigênio, e que Adam, sua contraparte (Doppelgänger) fisicamente idêntica da Terra Gêmea, não sabe que "água" no seu planeta consiste de XYZ. Adam $_{2}$, sendo uma exata duplicata de Adam 1 , terá várias das propriedades que Adam $_{1}$ têm. Dessa forma, ele estará disposto a aceitar a sentença escrita e pronunciada exatamente como a nossa sentença em português "água é molhada"16. Entretanto, os conteúdos dos estados mentais de $A_{d a m}$ e Adam $_{2}$ serão distintos, pois o pensamento de Adam 1 refere-se a $\mathrm{H}_{2} \mathrm{O}$, enquanto que o pensamento de $\mathrm{Adam}_{2}$ refere-se à XYZ. Assim, a palavra "água", na Terra Gêmea, não se refere à água. Água é um tipo natural cuja natureza essencial é a de possuir a estrutura química $\mathrm{H}_{2} \mathrm{O}$; e como não há $\mathrm{H}_{2} \mathrm{O}$ na Terra Gêmea, então não há água naquele planeta.

Como Adam $_{1}$ e Adam $_{2}$ possuem as mesmas propriedades intrínsecas e, mesmo assim, referem à substâncias distintas quando usam suas palavras "água", segue-se que tais propriedades intrínsecas não são suficientes para determinar sobre o que eles estão se referindo. Se concordarmos que um líquido com as propriedades superficiais de água, mas com diferente micro-estrutura não pode ser água ${ }^{17}$, então as maneiras de reconhecer o que é ou não água não pode ser dada pela intensão do termo. A determinação da sua extensão dependerá, então, de algo exterior ao indivíduo: as propriedades internas das coisas às quais o termo se aplica. Portanto, os conteúdos dos estados mentais que envolvem termos de tipo natural são amplos.

\footnotetext{
${ }^{14} \mathrm{Ou}$ seja, o líquido que possui as mesmas propriedades superficiais e as mesmas funções que a água no nosso mundo.

${ }^{15}$ Quem está familiarizado com tal experimento mental poderá estranhar a mudança do nome do sujeito - que normalmente é apresentado com o nome Oscar. Mas decidi nomear os indivíduos como "Adam" e "Adam.", aproximando da apresentação do experimento mental de Putnam feita por Burge em "Other Bodies" (1982, p. 86), pois no experimento mental da "artrite" de Burge o indivíduo também é nomeado como "Oscar", o que poderia gerar confusão sobre qual experimento está sendo referido se utilizasse, em ambos os experimentos, o mesmo nome.

${ }^{16}$ Podemos supor que tais sentenças são expressas na Terra Gêmea da mesma forma que nós as expressamos devido ao fato de supormos, inicialmente, que a Terra Gêmea possui uma história cultural idêntica à nossa. Dessa forma, XYZ foi batizado como sendo "água", da mesma forma que nós batizamos $\mathrm{H}_{2} \mathrm{O}$ como sendo "água". Creio que tal suposição, no experimento mental de Putnam, não seja problemática, pois o foco do exemplo está na relação dos termos com o ambiente físico apenas, e não em relação ao ambiente social.

17 "In fact, once we have discovered the nature of water, nothing counts as a possible world in which water doesn't have that nature. Once we have discovered that water (in the actual world) is $\mathrm{H}_{2} \mathrm{O}$, nothing counts as a possible world in which water isn't $\mathrm{H}_{2} \mathrm{O}$. In particular, if a 'logically possible' statement is one that holds in some 'logically possible world', it isn't logically possible that water isn't $\mathrm{H}_{2} \mathrm{O}$ ". PUTNAM, H. (1975). The Meaning of "Meaning". In: Mind, Language and Reality - Philosophical Papers. v. 2, Cambridge: Cambridge University Press, 1995, p. 233.
}

\begin{tabular}{|c|c|l|l|l|l|}
\hline intuitio & $\begin{array}{c}\text { ISSN } \\
1983-4012\end{array}$ & Porto Alegre & Vol.8 $-\mathrm{N}^{\mathrm{o}} .1$ & $\begin{array}{c}\text { Junho } \\
2015\end{array}$ & p.46-63 \\
\hline
\end{tabular}


O experimento mental de Burge ${ }^{18}$, por sua vez, funciona da seguinte forma: supomos, inicialmente, que Oscar tem várias crenças envolvendo o conceito ARTRITE. Ele tem, por exemplo, a crença de que artrite causa dor, de que seu pai sofria de artrite, de que ele tem artrite nos joelhos, ao começar a sentir dores frequentes na coxa, passa a crer também que a sua artrite no joelho aumentou e agora alcançou a sua coxa, ocasionando a dor que está sentido. Ele vai, então, ao médico e ao expressar a sua crença de que tem artrite na coxa, seu médico o corrige dizendo que artrite só ocorre nas articulações. Ao ouvir a correção do médico, Oscar a aceita e passa a acreditar que, o que quer que tenha na coxa, não é artrite. A segunda etapa do experimento mental consiste numa suposição contrafactual. Supomos novamente uma situação em que o paciente passa pelo mesmo curso de eventos físicos da situação real, até o momento em que ele relata o seu temor ao médico. Ele pronuncia e ouve as mesmas palavras nos mesmos momentos em que o faz na situação real. Mas suponha que na suposição contrafactual, médicos, lexicógrafos, e leigos bem-informados usam "artrite" não apenas para artrite, mas para várias outras moléstias reumatóides. Nesse caso, portanto, a crença do paciente estaria correta.

É razoável supor, então, que na situação contrafactual o paciente não pensa nem acredita que tem artrite na coxa, que tem artrite há anos, e assim por diante. "Artrite”, na situação contrafactual, difere da palavra "artrite" como é usada por nós, tanto na definição do dicionário quanto na sua extensão. Portanto, os conteúdos dos estados mentais do paciente na situação contrafactual diferem dos seus conteúdos reais. O resultado destas reflexões é: se os conteúdos mentais forem tomados isoladamente de seus contextos sociais, eles serão considerados como sendo idênticos. Assim, a diferença em seus conteúdos mentais é atribuível a diferenças em seu ambiente social, ou seja, a individuação dos estados e eventos mentais também depende da relação do sujeito com seu ambiente social.

O que os experimentos mentais, tanto o de Putnam quanto o de Burge nos mostram, é que podemos ter certos conceitos empregando-os nos nossos estados mentais (como crenças), mesmo que tenhamos uma compreensão parcial sobre eles e sobre suas referências. Segundo Burge, é em virtude das nossas interações com nossa comunidade linguística que temos certos conceitos e os usamos de certo modo. Não precisamos saber as condições de fixação da referência dos termos para sermos capazes de usá-los. Com isso, assumimos também que outros sujeitos possuem um conhecimento maior do que o nosso sobre os termos e as suas referências. $\mathrm{O}$ fato de que aprendemos os termos que utilizamos através de interações com outras pessoas, que achamos que sabem mais sobre a coisa em questão do que nós, e o fato de que aceitamos certas correções nos mostram que deferenciamos aos especialistas o uso correto destes termos. Putnam sugere isso como sendo uma "divisão do trabalho linguístico"19. Segundo ele, devido ao

\footnotetext{
${ }^{18}$ Cf. BURGE, T. (1979). Individualism and the Mental. In: Foundations of Mind. Oxford: Clarendon Press, 2007, p. 104.

${ }^{19}$ PUTNAM, H. (1975). The Meaning of "Meaning”. In: Mind, Language and Reality - Philosophical Papers. v. 2, Cambridge: Cambridge University Press, 1995, p. 227.
}

\begin{tabular}{|c|c|l|l|l|l|}
\hline intuitio & $\begin{array}{c}\text { ISSN } \\
1983-4012\end{array}$ & Porto Alegre & Vol.8 $-\mathrm{N}^{\mathrm{o}} .1$ & $\begin{array}{c}\text { Junho } \\
2015\end{array}$ & p.46-63 \\
\hline
\end{tabular}


fato de haver certos especialistas sobre as referências dos termos que utilizamos (como os casos de "água" e "artrite", por exemplo), nós não precisamos ter um conhecimento igualmente especializado sobre os nossos termos - nós podemos confiar no conhecimento destes especialistas. Desta forma, compreensão incompleta e deferencialidade parecem igualmente indicar, assim como os experimentos mentais, que os conteúdos dos estados mentais de um indivíduo são amplos.

\section{Conteúdos estreitos}

Contudo, como foi afirmado anteriormente, tal conteúdo amplo não parece capturar de modo completo o conteúdo representacional de uma crença. Por exemplo, suponha que uma criança, que ainda não teve aulas de matemática, profira a seguinte sentença: "há dois lápis naquele estojo". Qualquer mundo possível que verifique tal sentença será um que verifica "o número de lápis naquele estojo é o menor número primo". Dessa forma, a crença da criança tem o mesmo conteúdo que esta proposição. E, de certo modo, o conteúdo da sua crença tem de ser o mesmo que o da proposição - quando ela pensa sobre o numeral "dois", ela está pensando, em certo sentido, no menor número primo, pois o objeto do pensamento (a referência dos termos) é o mesmo. Entretanto, dificilmente atribuiremos à criança a crença de que "o número de lápis naquele estojo é o menor número primo", já que ela não sabe que o menor número primo é o número dois, nem mesmo o que é ser um número primo ${ }^{20}$.

Segundo Frank Jackson ${ }^{21}$, há outro sentido de semelhança e diferença que podemos dar aos conteúdos das nossas crenças. Quando usamos sentenças para capturar o que um sujeito acredita, precisamos distinguir duas questões: uma é se quando um sujeito representa as coisas, isso é igual a como uma ou outra proposição representa tais coisas. E a segunda questão é quando um sujeito pode saber sobre isso.

Vejamos mais detalhadamente um experimento mental semelhante ao de Putnam para compreendermos melhor tal distinção. Jackson ${ }^{22}$ propõe o experimento da seguinte forma: sua neta, evidentemente, mora na Terra. A contraparte gêmea da sua neta, por sua vez, mora na Terra Gêmea. Assim como na versão de Putnam, a neta e a sua contraparte são idênticas internamente e a única diferença entre uma situação e outra é que a neta vive onde o líquido potável e inodoro conhecido pelos habitantes sob o nome de "água" é $\mathrm{H}_{2} \mathrm{O}$, enquanto que a contraparte vive onde o líquido potável e inodoro

\footnotetext{
${ }^{20} \mathrm{Cf}$. Jackson aponta: "normally we require, as a necessary condition for believing that the number is the smallest prime, possession of the concept of a prime number, and she does not (as yet) possess that concept". JACKSON, F. Representation and Narrow Belief. In: Philosophical Issues, n. 13, v. 1, pp. 99-112, 2003b, p. 101.

${ }^{21}$ Cf. JACKSON, F. Representation and Narrow Belief. In: Philosophical Issues, n. 13, v. 1, pp. 99-112, 2003b, p. 100.

${ }^{22}$ Cf. JACKSON, F. Representation and Narrow Belief. In: Philosophical Issues, n. 13, v. 1, pp. 99-112, 2003b, p. 102-103.
}

\begin{tabular}{|c|c|c|c|c|c|}
\hline intuitio & $\begin{array}{c}\text { ISSN } \\
1983-4012\end{array}$ & Porto Alegre & Vol.8 $-\mathrm{N}^{\circ} .1$ & $\begin{array}{c}\text { Junho } \\
2015\end{array}$ & p.46-63 \\
\hline
\end{tabular}


conhecido pelos habitantes sob o nome de "água" é XYZ. Concordamos que "água", dito pela neta referese à $\mathrm{H}_{2} \mathrm{O}$ e que "água", dito pela sua contraparte refere-se à XYZ. Tanto a neta quanto a sua contraparte usam a palavra "água" para certa coisa ao seu redor de certo tipo, e a coisa ao redor de uma é $\mathrm{H}_{2} \mathrm{O}$ enquanto que da outra é XYZ. E, por último, a neta é altamente competente com o uso do termo "água", mas ainda não teve, por exemplo, aula de Química, e não sabe que água é $\mathrm{H}_{2} \mathrm{O}$. Por sua vez, sua contraparte também é altamente competente com o uso da palavra "água" na sua língua e também ainda não teve aula de Química nem nada que pudesse levá-la a saber que água no seu mundo é XYZ. Como vimos, os conteúdos das crenças da neta e da sua contraparte serão, então, distintos pois as referências e, com isso, as condições de valor de verdade diferem. Se ambas são idênticas internamente, mas seus conteúdos diferem, isso significa que o ambiente externo faz parte da determinação do conteúdo. Estes conteúdos, então, são amplos.

E isso implica que as crenças da neta sobre água possuem o mesmo conteúdo que as sentenças sobre $\mathrm{H}_{2} \mathrm{O}$. Mas, assim como no nosso exemplo com sentenças matemáticas, parece contra intuitivo atribuirmos à neta crenças sobre $\mathrm{H}_{2} \mathrm{O}$. Quando dizemos que ela acredita que água é incolor, por exemplo, não dizemos igualmente que ela acredita que $\mathrm{H}_{2} \mathrm{O}$ seja incolor. Num certo sentido extensional, suas crenças sobre "água" são crenças sobre $\mathrm{H}_{2} \mathrm{O}$, pois ambas mapeiam os mesmos mundos possíveis. Mas num sentido representacional, não parece funcionar do mesmo modo. A neta de Jackson não representa o mundo como sendo constituído de $\mathrm{H}_{2} \mathrm{O}$, muito menos representa "água" como sendo a mesma coisa que $\mathrm{H}_{2} \mathrm{O}$.

Para fazer um mapeamento dos estados possíveis que são consistentes com a crença da neta devemos levar em consideração o modo como ela representa como as coisas são, ou seja, devemos usar o que ela acredita sobre como o mundo é. E o que ela acredita ser água, como uma falante que domina o termo, são suas propriedades superficiais daquilo que está ao seu redor - líquido, insípido, inodoro, incolor, e assim por diante. Nesse sentido, agora, o conteúdo da crença da neta e da sua contraparte são iguais, ou seja, selecionam os mesmos estados possíveis do mundo, pois ambas representam "água" da mesma forma. Portanto, os conteúdos das suas crenças não são apenas amplos, mas, em certo sentido, também são estreitos.

No entanto, para capturarmos o conteúdo estreito de um estado mental, não podemos utilizar os habituais mundos possíveis de Kripke, pois eles trazem consigo uma complicação para a determinação de tal conteúdo: o problema é que mundos possíveis não bastam para capturar o conteúdo egocêntrico de uma crença.

\begin{tabular}{|c|c|c|c|c|c|}
\hline intuitio & $\begin{array}{c}\text { ISSN } \\
1983-4012\end{array}$ & Porto Alegre & Vol.8 $-\mathrm{N}^{\circ} .1$ & $\begin{array}{c}\text { Junho } \\
2015\end{array}$ & p.46-63 \\
\hline
\end{tabular}


Muito do que dizemos e acreditamos, é egocêntrico no sentido de ter um tipo de autoreferência embutida $^{23}$. Por exemplo, quando falo de "água", falo da coisa aquosa que preenche mares, cai do céu, etc, que está ao meu redor. É preciso, então, determinar o centro como o sujeito do estado mental em questão, ou seja, precisamos de mundos centrados ${ }^{24}$. Além disso, quando comunico como as coisas são usando uma sentença $\mathrm{S}$, estou comunicando que tipo de mundo é esse em que estamos, ou seja, o mundo atual de acordo com S. E os mundos que devem ser atuais de acordo com S são os mundos $\mathrm{W}$ tal que W, sendo atual, é consistente com S sendo verdadeira. Portanto, a noção de mundos possíveis não pode ser utilizada para a determinação do conteúdo estreito, pois a contrafactualidade é sempre pensada em relação a este mundo como sendo o atual.

O ponto fundamental para Jackson é que podemos dizer que há dois $\operatorname{modos}^{25}$ de se pensar a possibilidade de uma sentença: podemos pensar uma possibilidade, ou "mundo possível", como um contexto de avaliação, e podemos pensar um mundo possível como um contexto de proferimento. Kripke, quando define mundos possíveis e afirma que nomes próprios são designadores rígidos, só está pensando no primeiro tipo de possibilidade. Nessa interpretação, um mundo possível é uma situação estipulada, tendo como parâmetro o nosso mundo. Assim, a linguagem já está fixada e permanece constante: os sentidos e as referências são as mesmas que as do nosso mundo.

Contudo, quando falamos ou pensamos que uma referência ou sentido de um termo poderia ser diferente, ou que o nosso mundo poderia não ser como ele de fato é, ou quando o representamos de acordo com aquilo que acreditamos sobre o modo como ele parece ser não estamos estipulando mundos contrafactuais e avaliando tais sentenças. O que nós fazemos é pensar em um mundo possível como se fosse o nosso mundo, tomando-o como se fosse o mundo real. Nesse caso, consideramos a aplicação de um termo sobre várias hipóteses de que um determinado mundo $\mathrm{W}$ é o mundo atual, o nosso mundo.

\section{Intensões A e intensões C}

${ }^{23}$ Cf. JACKSON, F. Why we need A-Intensions. In: Philosophical Studies, v. 118, n. 1-2, pp. 257-277, Mar., 2004, p. 259.

${ }^{24}$ Cf. JACKSON, F. Narrow Content and representation - or Twin Earth revisited. In: Proceedings and Addresses of the American Philosophical Association. v. 77, n. 2, pp. 55-70, Nov., 2003a, p. 8-11. Disponível em: http://phil.arts.cuhk.edu.hk/ phidept/TCIVP/jackson/FJ\%20Narrow\%20content.pdf.

25 "We can think of the various possible particulars, situations, events, or whatever to which a term applies in two different ways, depending on whether we are considering what the term applies to under various hypotheses about which world is the actual world, or whether we are considering what the term applies to under various counterfactual hypotheses". JACKSON, F. From Metaphysics to Ethics: a Defense of Conceptual Analysis. USA: Oxford University Press, 2000, p. 47-48.

\begin{tabular}{|c|c|c|c|c|c|}
\hline intuitio & $\begin{array}{c}\text { ISSN } \\
1983-4012\end{array}$ & Porto Alegre & Vol.8 $-\mathrm{N}^{\mathrm{o}} .1$ & $\begin{array}{c}\text { Junho } \\
2015\end{array}$ & p.46-63 \\
\hline
\end{tabular}


Para capturar estes dois tipos de possibilidades, há ainda dois tipos de intensões ${ }^{26}$ : no caso do mundo possível centrado pensado como atual, têm-se a extensão-A de um termo T em um mundo W (A de atual), e a função que assinala, em cada mundo $\mathrm{W}$, a extensão-A de T é a sua intensão-A. Já no segundo caso, o mundo real está fixado e os demais mundos são pensados como contrafactuais e, com isso, T se aplica à mesma coisa em todos os mundos. Neste caso, temos então a extensão-C de um termo em W (C de contrafactual) e a função que assinala em cada mundo a extensão-C de T é a sua intensão- $C$.

Em algumas sentenças as intensões-A de um termo serão as mesmas que as suas intensões-C. Um exemplo disso é o da palavra "quadrado". As coisas em um mundo a que a palavra "quadrado" se aplica sob a hipótese de que aquele mundo é atual são as mesmas coisas que a palavra "quadrado" seleciona sob a hipótese de que aquele mundo é um mundo contrafactual. Para esses casos, as condições de valor de verdade em um mundo contrafactual e as condições de valor de verdade em um mundo sob a suposição de que ele é atual são as mesmas.

Assim, de acordo com a proposta bidimensionalista, a extensão-A do termo "água" em um mundo W pensado como atual será a coisa aquosa de nossa percepção [acquaintance] naquele mundo, e a extensão-C será, necessariamente, $\mathrm{H}_{2} \mathrm{O}$. E tal determinação da referência em um mundo pensado como atual, não será dada simplesmente por uma relação causal entre o sujeito e o ambiente externo do mundo real, mas sim levando em consideração aquilo que o sujeito acredita e sabe sobre a extensão do termo - ou seja, por um conjunto de descrições. No caso de "água", podemos dizer que a sua extensão-A em um mundo W é determinada pela crença do sujeito de que "água" é a "coisa líquida, insípida, que cai sob a forma de chuva, etc" ${ }^{27}$.

Obviamente, seria uma tarefa mais fácil para a construção de uma teoria bidimensionalista se todos concordassem que um termo como "água" é um termo em que a fixação da referência é dada por alguma descrição. A descrição relevante, como vimos, seria algo como "coisa aquosa", falada do modo habitual: o líquido claro de nossa percepção que cai do céu, que preenche oceanos e assim por diante. Isto tornaria "água" equivalente à "a atual coisa aquosa", e porque a coisa aquosa é $\mathrm{H}_{2} \mathrm{O}$ no mundo real isto faria com que "há água" e "há $\mathrm{H}_{2} \mathrm{O}$ " sejam verdadeiras exatamente nos mesmos mundos, pois ambas têm a mesma intensão-C. E, como vimos, também explicaríamos a diferença nos conteúdos representacionais de "há água" e "há $\mathrm{H}_{2} \mathrm{O}$ ", notando que "há água" é equivalente a "há uma coisa aquosa atual" e que o

${ }^{26}$ Cf. JACKSON, F. From Metaphysics to Ethics: a Defense of Conceptual Analysis. USA: Oxford University Press, 2000, p.48-49.

${ }^{27}$ Mas isso não quer dizer que toda extensão-A de um termo será determinada apenas por suas propriedades superficiais, pois ela também poderá ser selecionada em um mundo $\mathrm{W}$ pela sua natureza oculta, sendo distinta da extensão-C em alguns mundos. Por exemplo, estudantes iniciantes de química selecionam os ácidos pela propriedade superficial de mudança de cor de um certo papel para vermelho, mesmo sabendo que "ácido" é aplicado à algo em virtude de ter uma natureza oculta que tem um papel específico e significante na teoria química e sobre a qual eles esperam aprender nas suas aulas futuras. Cf. JACKSON, F. From Metaphysics to Ethics: a Defense of Conceptual Analysis. USA: Oxford University Press, 2000, p. 49.

\begin{tabular}{|c|c|c|c|c|c|}
\hline intuitio & $\begin{array}{c}\text { ISSN } \\
1983-4012\end{array}$ & Porto Alegre & Vol.8 $-\mathrm{N}^{\circ} .1$ & $\begin{array}{c}\text { Junho } \\
2015\end{array}$ & p.46-63 \\
\hline
\end{tabular}


conteúdo representacional dessa sentença é o conjunto de mundos onde há a coisa aquosa, a sua intensãoA, enquanto que a intensão-A de "há $\mathrm{H}_{2} \mathrm{O}$ ", por sua vez, seria o conjunto de mundos onde há $\mathrm{H}_{2} \mathrm{O}$.

Contudo, segundo defensores do externalismo, não há uma coisa como $a$ propriedade que fixa a referência de "água". Tais defensores afirmam que as referências dos termos como "água" e "olmo" não são dadas por propriedades associadas, mas sim por algo sobre o qual os falantes não precisam saber nada: um tipo de relação causal. Se for assim, então a sugestão de que usamos intensões-A para capturar o conteúdo dos nossos estados mentais não teria qualquer plausibilidade, pois não haveria propriedades adequadas que pudessem satisfazer a noção de intensão-A requerida.

Jackson argumenta, no entanto, que há tais propriedades ${ }^{28}$. Isto porque, em primeiro lugar, nossa habilidade de usar a linguagem para transmitir informações sobre o nosso mundo nos mostra que muitas palavras estão associadas a propriedades conhecidas ${ }^{29}$. Supor de outra maneira tornaria sem sentido a nossa habilidade para comunicar perspectivas sobre a distribuição de propriedades usando palavras. $\mathrm{O}$ segundo ponto é que algumas dessas associações são altamente resilientes [resilient]. Nós somos capazes de falar e escrever de forma sensata sobre situações que sabemos que com certeza não existem. E consideramos frequentemente a resiliência como garantida, como quando conversamos sobre possibilidades. E, finalmente, as associações são propriedades semânticas das palavras no sentido de que o conhecimento delas é parte do que está envolvido em compreender uma língua. Pessoas que compreendem uma língua como o português, por exemplo, são capazes de usá-la para relatar, aprender sobre e discutir uma vasta gama de concatenações possíveis de propriedades. Tais propriedades, Jackson denomina de propriedades representacionais $^{30}$.

Se os falantes de uma língua (no nosso caso, o português) podem dizer o que chamar de "água" quando várias possibilidades são descritas a eles, então podemos identificar a propriedade representacional para a palavra "água": a propriedade que, mesmo implícita, os guia quando dizem que uma coisa em cada possibilidade é ou não "água”. Assim, há uma propriedade representacional para a palavra "água", e as intuições sobre o que conta como "água" são partes do exercício de fazer explícito o nosso conhecimento da propriedade de "ser água".

${ }^{28}$ Cf. JACKSON, F. Why we need A-Intensions. In: Philosophical Studies, v. 118, n. 1-2, pp. 257-277, Mar., 2004, p. 266-267.

${ }^{29}$ Quero deixar claro aqui que essa visão de que uma teoria da referência direta exclui qualquer tipo de descrição associada a uma palavra é a de Jackson. Nem Kripke nem Putnam negam a existência de descrições associadas aos termos. O que as suas teorias negam é que tais descrições sejam o suficiente para a determinação da referência, ou ainda que tais descrições sejam necessárias para a determinação da referência. Tanto que em Putnam as descrições estão presentes como marcadores semânticos, sintáticos e os estereótipos (sendo os estereótipos o que Jackson coloca como "descrições habituais" - o fato de água ser incolor, insípida, e por ai vai). É claro que os textos de Kripke e Putnam mostram que é possível que um termo tenha referência sem ter nenhuma descrição associada, mas disso não se segue que todos os termos não têm nenhuma descrição associada.

${ }^{30}$ Cf. JACKSON, F. Why we need A-Intensions. In: Philosophical Studies, v. 118, n. 1-2, pp. 257-277, Mar., 2004, p. 270.

\begin{tabular}{|c|c|l|l|l|l|}
\hline intuitio & $\begin{array}{c}\text { ISSN } \\
1983-4012\end{array}$ & Porto Alegre & Vol.8 $-\mathrm{N}^{\circ} .1$ & $\begin{array}{c}\text { Junho } \\
2015\end{array}$ & p.46-63 \\
\hline
\end{tabular}


Quando uma versão apropriada do cenário da Terra Gêmea é descrita para nós, podemos vir a concordar que $\mathrm{H}_{2} \mathrm{O}$ na Terra Gêmea pode não ter nenhuma das propriedades superficiais que comumente associamos e, ainda assim, ser água. A intuição de que $\mathrm{H}_{2} \mathrm{O}$ é "água" na Terra Gêmea vem do fato de que $\mathrm{H}_{2} \mathrm{O}$ é o que chamamos de "água" na Terra. Mas se viermos a duvidar que $\mathrm{H}_{2} \mathrm{O}$ é a coisa aquosa na Terra, por exemplo, se retornarmos ao nosso estado epistêmico pré-Lavoisier, nós correspondentemente duvidaremos que $\mathrm{H}_{2} \mathrm{O}$ na Terra Gêmea seja água. Isso nos mostra que a propriedade que consideramos como relevante (neste caso, ser $\mathrm{H}_{2} \mathrm{O}$ ) é aquela com a qual estamos familiarizados e interagimos, ou seja, é egocêntrica no sentido de ser a coisa-aquosa ao nosso redor. É a propriedade egocêntrica ${ }^{31}$ que fornece a referência do termo "água" na Terra Gêmea.

Há, então, uma diferença crucial entre o status epistêmico da extensão-A de um termo e a sua extensão- $\mathrm{C}^{32}$. Para saber a extensão-C de um termo, precisamos saber algo sobre o mundo atual. O ponto é, que para selecionar "água" em um mundo contrafactual, precisamos saber algo sobre as relações entre o mundo contrafactual e o mundo atual, que só podemos saber após descobrir que no mundo atual "água" é $\mathrm{H}_{2} \mathrm{O}$. Mas, em contrapartida, sabemos a priori a extensão-A de "água" em cada mundo pensado como o atual, pois selecioná-la não depende da natureza real do mundo, já que a determinação da extensão-A depende apenas das descrições que associamos a tal termo. Ignorância sobre o mundo atual não faz diferença para o conhecimento das extensões-A dos diferentes mundos, enquanto que o conhecimento da extensão-C requer um conhecimento dos fatos relevantes sobre o mundo real. Além disso, quando a intensão-A difere da intensão-C também é um conhecimento que independe de como o mundo atual é. As intensões $\mathrm{A}$ e $\mathrm{C}$ de um termo diferirão se e somente se as suas extensões em um mundo variarem de acordo com uma dada suposição de que tal mundo é atual. E quando isto é ou não o caso é independente do conhecimento de qual mundo é de fato o atual. Assim, de acordo com a semântica bidimensional, há dois casos de aprioricidade: um é acerca do conhecimento da intensão-A de vários termos e o outro é sobre quando as intensões-A e $\mathrm{C}$ dos termos diferem ${ }^{33}$. Portanto, sabemos a priori o fato de que as extensões-A de "água" em qualquer mundo é a coisa aquosa de nossa percepção [acquaintance], e também sabemos a priori o fato de que a extensão-C de "água" em alguns mundos W difere da coisa aquosa de nossa percepção em W.

${ }^{31}$ Cf. JACKSON, F. Why we need A-Intensions. In: Philosophical Studies, v. 118, n. 1-2, pp. 257-277, Mar., 2004, p. 274.

${ }^{32}$ Cf. JACKSON, F. From Metaphysics to Ethics: a Defense of Conceptual Analysis. USA: Oxford University Press, 2000, p. 50.

33 "So there are two a priori parts to the conceptual analysis story: the part concerned with the A-intensions of various terms, and the part concerned with whether the A-intensions and $\mathrm{C}$-intensions of various terms differ. For instance, it is a priori that the A-extension of 'water' at any world is the watery stuff of our acquaintance, and also $a$ priori that the C-extension of 'water' at some $w$ differs from the watery stuff of our acquaintance at $w$ ". JACKSON, F. From Metaphysics to Ethics: a Defense of Conceptual Analysis. USA: Oxford University Press, 2000, p. 52.

\begin{tabular}{|c|c|c|c|c|c|}
\hline intuitio & $\begin{array}{c}\text { ISSN } \\
1983-4012\end{array}$ & Porto Alegre & Vol. $8-\mathrm{N}^{\circ} .1$ & $\begin{array}{c}\text { Junho } \\
2015\end{array}$ & p.46-63 \\
\hline
\end{tabular}




\section{Compreensão incompleta e conteúdo estreito}

Como vimos anteriormente, os experimentos mentais apresentados em defesa do externalismo semântico nos mostram que, para sermos falantes competentes de um determinado termo, não precisamos ter uma compreensão completa sobre a sua aplicação. Segundo Burge, uma das lições que podemos tirar do seu experimento mental é a de que a compreensão linguística e conceitual comumente não está baseada em um domínio por parte do sujeito de princípios constitutivos ${ }^{34}$ que governam o uso dos termos. A razão para isto, segundo ele, é que tais princípios constitutivos dependem da natureza da res relevante, e tal natureza não está facilmente disponível para nós - ela exige estudos e investigações.

Desse modo, posso ter a crença "água cobre mais de $60 \%$ do planeta Terra", por exemplo, e tal crença não depende que eu saiba que água é, necessariamente, $\mathrm{H}_{2} \mathrm{O}$. Mas sendo água necessariamente $\mathrm{H}_{2} \mathrm{O}$, a determinação do valor de verdade da minha crença envolve a questão sobre se $\mathrm{H}_{2} \mathrm{O}$ cobre ou não mais de $60 \%$ da Terra. No sentido das condições de verdade de uma sentença, a proposição expressa pela minha crença sobre água depende de como as coisas são no mundo atual, em particular, depende de quando a coisa aquosa de nossa percepção [acquaintance] é $\mathrm{H}_{2} 0$. Jackson conclui, assim como Burge, que compreender a sentença "água cobre mais de $60 \%$ da Terra" não requer um conhecimento das condições sob a qual ela é verdadeira. Segundo Jackson, isso quer dizer que aqueles que não sabem que água é composta de dois átomos de hidrogênio e um de oxigênio igualmente não sabem a proposição expressa ${ }^{35}$ por sentenças que contém o termo "água". Eles podem saber tudo que há para ser conhecido sobre um mundo contrafactual (todas as condições estipuladas sobre tal mundo) sem saber, com isso, se a sentença que proferem é verdadeira ou falsa naquele mundo, devido a sua ignorância sobre o mundo atual. Mesmo assim, eles compreendem sentenças sobre "água". Portanto, afirma Jackson, tal compreensão requer antes um conhecimento de como a sentença expressa depende do seu contexto de proferimento - nesse caso, de como ela depende da coisa no mundo do proferimento, que é a coisa aquosa de nossa percepção no mundo atual $^{36}$.

\footnotetext{
${ }^{34}$ Exemplos de "princípios constitutivos" (ou "princípios explicativos") são "átomos são partículas indivisíveis", "artrite ocorre apenas nas articulações" e "água é $\mathrm{H}_{2} \mathrm{O}$ ". BURGE, T. (2006). Postscript to "Individualism and the Mental'. In: Foundations of Mind. Oxford: Clarendon Press, 2007, p. 163.

${ }^{35}$ Cf. JACKSON, F. From Metaphysics to Ethics: a Defense of Conceptual Analysis. USA: Oxford University Press, 2000, p. 73.

36 "Nevertheless, they understand 'water' sentences. It follows that understanding 'Water covers most of the Earth' does not require knowing the conditions under which it is true, that is, the proposition it expresses. Rather it requires knowing how the proposition expressed depends on context of utterance-in this case, how it depends on which stuff in the world of utterance is the watery stuff of our acquaintance in it". JACKSON, F. From Metaphysics to Ethics: a Defense of Conceptual Analysis. USA: Oxford University Press, 2000, p. 73-74.
}

\begin{tabular}{|c|c|c|c|c|c|}
\hline intuitio & $\begin{array}{c}\text { ISSN } \\
1983-4012\end{array}$ & Porto Alegre & Vol.8 $-\mathrm{N}^{\circ} .1$ & $\begin{array}{c}\text { Junho } \\
2015\end{array}$ & p.46-63 \\
\hline
\end{tabular}


Contudo, saber como a proposição depende do contexto é saber as condições de valor de verdade em outro sentido de "as condições de valor de verdade da sentença" ${ }^{\text {37 }}$. Por exemplo, o conhecimento requerido para compreender "água cobre mais de 60\% da Terra" pode ser dado da seguinte forma: "se $\mathrm{H}_{2} \mathrm{O}$ é a coisa aquosa que estamos atualmente percebendo, então 'água cobre mais de $60 \%$ da Terra' expressa uma proposição que é verdadeira se e somente se $\mathrm{H}_{2} \mathrm{O}$ cobre mais de $60 \%$ da Terra". Todavia, se $\mathrm{XYZ}$ for a coisa aquosa que estamos atualmente percebendo, então "água cobre mais de $60 \%$ da Terra" expressa uma proposição que é verdadeira se e somente se XYZ cobre mais de $60 \%$ da Terra. Assim, nesse sentido, o sujeito que produz a sentença sabe as suas condições de valor de verdade. De acordo com Jackson, então, há duas proposições conectadas a uma sentença como "água cobre mais de $60 \%$ da Terra": em uma, as condições de valor de verdade da proposição expressa é um conjunto de mundos no qual a sentença é verdadeira dado que um dos mundos é de fato o mundo real e, na outra, as condições de valor de verdade da proposição expressa é o conjunto de mundos que satisfazem a condição de que se W for o mundo atual então a sentença é verdadeira em $\mathrm{W}^{38}$. Neste segundo caso estamos considerando, para cada mundo W, o valor de verdade de $\mathrm{S}$ em W sob a suposição de que W é o mundo atual. Então, esta será a proposição-A de $\mathrm{S}$, enquanto que a primeira será a proposição-C de $\mathrm{S}$.

Tal bidimensionalismo nos mostra que compreender sozinho uma sentença não nos dá a proposição expressa, ou seja, não nos dá a proposição-C. O que a nossa compreensão nos dá é o modo que a proposição expressa depende do contexto, dos fatos relevantes que estão "fora da cabeça". É, então, a proposição-A expressa por uma sentença que mais bem captura o que alguém acredita e a informação que ele deseja transmitir ao proferir uma sentença. Assim, uma criança que ainda não teve aulas de química em que poderiam ter-lhe ensinado que água é $\mathrm{H}_{2} \mathrm{O}$, mas que compreende a frase "água cobre a maior parte do nosso planeta" poderá usar a sentença para expressar a sua opinião de que a maior parte da Terra é coberta pelo material aquoso de sua percepção [acquaintance]. E, em geral, é a proposição-A que conhecemos em virtude de compreendermos uma sentença.

Visto desse modo, a proposição-A é um tipo de conteúdo estreito. Considere novamente o caso da Terra Gêmea. Tanto Adam 1 quanto sua contraparte tem crenças que expressam dizendo "nuvens contém água". Considere a intensão-A da crença B1 de Adam $_{1}$ e a intensão-A da crença B2 de Adam 2 . Seja W1 o

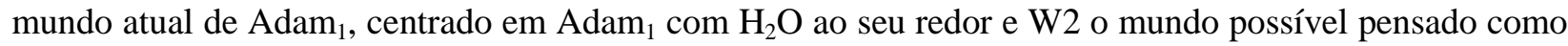
atual de $\mathrm{Adam}_{2}$, centrado em $\mathrm{Adam}_{2}$ com XYZ ao seu redor em oceanos, lagos e nuvens. Claramente, B1 e B2 são verdadeiras: a intensão-A de B1 é verdadeira em W1 e a intensão-A de B2 é verdadeira em W2.

${ }^{37}$ JACKSON, F. From Metaphysics to Ethics: a Defense of Conceptual Analysis. USA: Oxford University Press, 2000, p. 75.

38 "Accordingly, we could say, following Tichy, Chalmers, Lewis, and Stalnaker among others, that there are two propositions connected with a sentence like "Water covers most ofthe Earth". JACKSON, F. From Metaphysics to Ethics: a Defense of Conceptual Analysis. USA: Oxford University Press, 2000, p. 76.

\begin{tabular}{|c|c|l|l|l|l|}
\hline intuitio & $\begin{array}{c}\text { ISSN } \\
1983-4012\end{array}$ & Porto Alegre & Vol.8 $-\mathrm{N}^{\circ} .1$ & $\begin{array}{c}\text { Junho } \\
2015\end{array}$ & p.46-63 \\
\hline
\end{tabular}


Além disso, a intensão-A de B1 também é verdadeira em W2: se Adam 1 aceitar que W2 é atual, então ele deverá racionalmente aceitar B1. Simetricamente, a intensão-A de B2 é verdadeira em W1. Assim, tanto a intensão-A de B1 quanto a de B2 são verdadeiras em W1 e W2.

Como vimos a intensão-A seleciona em um dado mundo $\mathrm{W}$ (tomado como sendo o atual) uma substância no ambiente do centro (do sujeito), baseado no papel da substância naquele mundo e nas suas propriedades superficiais. Podemos dizer que ambas as crenças endossam tais mundos centrados nos quais o líquido claro e bebível ao redor do centro do mundo está presente em alguma forma nas nuvens ao redor do centro do mundo, ou seja, em W1 a intensão-A de ambos os conceitos selecionam $\mathrm{H}_{2} \mathrm{O}$ e em W2 ambas selecionam XYZ. Desse modo, se algum mundo centrado $\mathrm{W}$ tomado como atual verifica a crença de Adam $_{1}$ B1, tal mundo também verificará a crença B2 da sua contraparte. E se W falsifica B1 também falsifica B2. Assim, ambas dividem o espaço lógico do mesmo modo. Consequentemente, podemos dizer que as duas crenças possuem a mesma intensão-A, a mesma referência e as mesmas condições de valor de verdade, ou seja, elas têm o mesmo conteúdo e, com isso, seus conteúdos são estreitos.

\section{Conclusão}

Portanto, o caso da Terra Gêmea de Putnam não é um argumento suficiente contra o conteúdo estreito defendido pelo bidimensionalismo, pelo contrário, ele mesmo pode ser utilizado para defender tal forma de conteúdo. Além disso, considerando conteúdos como sendo representacionais, mudanças no ambiente parecem não fazer alterações nos conteúdos dos estados mentais, mesmo se considerarmos mudanças no ambiente social, como nos exemplos de Burge. Colocando de outro modo: de certa forma os conteúdos permanecem os mesmos. A defesa do conteúdo amplo através dos experimentos mentais é, na verdade, falha, pois confunde uma questão de segunda ordem com uma de primeira ordem.

Uma questão de primeira ordem é aquela que diz respeito à quais são os conteúdos e as referências das nossas palavras e pensamentos. Já uma de segunda ordem é relativa ao que faz ser o caso de que eles são o que são. A questão de saber se podemos mudar os conteúdos apenas mudando os ambientes dos sujeitos, está relacionada mais diretamente a porque nossas palavras e estados intencionais têm os conteúdos que eles têm - uma questão de segunda ordem. Contudo, qualquer discussão sobre conteúdo que apele a intuições sobre casos possíveis estará relacionada à quais são os conteúdos de nossos termos e pensamentos - uma questão de primeira ordem. Por exemplo, intuições sobre o que dizer usando a palavra "água" em uma ou outra versão da Terra Gêmea, incidem sobre a referência da palavra "água" no nosso mundo, não sobre porque aquele termo tem que ter aquela referência.

Assim, Jackson acredita ter um argumento que mostra que "água" é um termo com referência fixada via uma propriedade: a sua propriedade representacional. E isto completa o caso para a solução

\begin{tabular}{|c|c|l|l|l|l|}
\hline intuitio & $\begin{array}{c}\text { ISSN } \\
1983-4012\end{array}$ & Porto Alegre & Vol.8 $-\mathrm{N}^{\mathrm{o}} .1$ & $\begin{array}{c}\text { Junho } \\
2015\end{array}$ & p.46-63 \\
\hline
\end{tabular}


apresentada anteriormente do porque o conteúdo representacional de, por exemplo, "há água" é diferente do conteúdo de "há $\mathrm{H}_{2} \mathrm{O}$ ", mesmo água sendo necessariamente $\mathrm{H}_{2} \mathrm{O}$. As intensões-A das sentenças diferem, e são elas que dão o conteúdo representacional de um estado mental. A intensão-A de "há água" é o conjunto de mundos onde aquilo que tem a propriedade representacional de ser uma coisa aquosa existe. Isto é plausível como sendo o que queremos transmitir quando dizemos que há água e, é um conjunto diferente daquele onde há $\mathrm{H}_{2} \mathrm{O}$.

Dessa forma, o argumento bidimensionalista nos mostra que há dois modos de considerarmos sobre qual seria a conclusão dos experimentos mentais da Terra Gêmea, e que há dois modos de se considerar o conteúdo de um estado mental: no seu sentido extensional, onde a referência é fixada no mundo real, e no seu sentido representacional, onde o modo como o sujeito representa o mundo é relevante na fixação da referência, sendo tal referência fixada em mundos possíveis tomados como atuais. Logo, os experimentos mentais tanto podem nos mostrar que os conteúdos dos estados mentais são amplos, quanto que podemos considerar que os conteúdos destes estados são estreitos. E, devido aos dois modos de se considerar a possibilidade, ou seja, considerar um mundo possível como contexto de avaliação ou como contexto de proferimento, podemos plausivelmente afirmar que há uma dupla dimensão nos nossos estados mentais e, portanto, afirmar que tais estados tanto possuem conteúdos amplos quanto conteúdos estreitos. Dessa forma, há um bom argumento em favor do bidimensionalismo semântico em relação à atribuição de conteúdos aos nossos estados mentais.

\section{Referências}

BURGE, T. Other Bodies. In: Foundations of Mind, Clarendon Press, Oxford, 2007.

Individualism and the Mental. In: Foundations of Mind. Oxford: Clarendon Press, 2007.

. Postscript to 'Individualism and the Mental'. In: Foundations of Mind. Oxford: Clarendon Press, 2007.

Foundations of Mind, Clarendon Press, Oxford, 2007.

JACKSON, F. Narrow Content and representation - or Twin Earth revisited. In: Proceedings and Addresses of the American Philosophical Association, v.77, n. 2, pp. 55-70, Nov., 2003a. Disponível em: http://phil.arts.cuhk.edu.hk/ phidept/TCIVP/jackson/FJ\%20Narrow\%20content.pdf.

. From Metaphysics to Ethics: a Defense of Conceptual Analysis. USA: Oxford University Press, 2000.

Representation and Narrow Belief. In: Philosophical Issues, n. 13, v. 1, pp. 99-112, 2003b.

Why we need A-Intensions. In: Philosophical Studies, v. 118, n. 1-2, pp. 257-277, Mar., 2004.

KRIPKE, S. Naming and Necessity. In: The Philosophy of Language. ed. A. P. Martinich, 3ed. Oxford: University Press, 1996.

MARQUES, E. Putnam e a possibilidade de determinação de essências a partir de critérios semânticos. In: Sintese Nova Fase, Belo Horizonte, v. 26, n. 84, pp. 107-118, 1999.

PUTNAM, H. The Meaning of "Meaning". In: Mind, Language and Reality - Philosophical Papers. v. 2, Cambridge: Cambridge University Press, 1995.

PEREIRA, R. H. O conteúdo exíguo segundo uma ótica anti-individualista. In: Analytica, Rio de Janeiro, v. 13 n. 1, pp. 213-256, 2009.

SCHROETER, L. "Two-Dimensional Semantics" In: The Stanford Encyclopedia of Philosophy (Winter 2012 Edition), Edward N. Zalta (ed.). Disponível em: <http://plato.stanford.edu/archives/win2012/entries/twodimensional-semantics/>.

\begin{tabular}{|c|c|c|c|c|c|}
\hline intuitio & $\begin{array}{c}\text { ISSN } \\
1983-4012\end{array}$ & Porto Alegre & Vol.8 $-\mathrm{N}^{\circ} .1$ & $\begin{array}{c}\text { Junho } \\
2015\end{array}$ & p.46-63 \\
\hline
\end{tabular}


Recebido em: 20/05/2014

Aprovado para publicação em: 14/10/2014

\begin{tabular}{|c|c|l|l|l|l|}
\hline intuitio & $\begin{array}{c}\text { ISSN } \\
1983-4012\end{array}$ & Porto Alegre & Vol.8 $-\mathrm{N}^{\mathrm{o}} .1$ & $\begin{array}{c}\text { Junho } \\
2015\end{array}$ & p.46-63 \\
\hline
\end{tabular}

